\title{
Clinically relevant lessons from Family HealthLink: a cancer and coronary heart disease familial risk assessment tool
}

\author{
Kevin Sweet, MS1, Amy C. Sturm, MS ${ }^{1,2}$, Amy Rettig, RN, ACNS-BC ${ }^{3}$, Joseph McElroy, PhD ${ }^{4}$ and \\ Doreen Agnese, $\mathrm{MD}^{1,5}$
}

Purpose: A descriptive retrospective study was performed using two separate user cohorts to determine the effectiveness of Family HealthLink as a clinical triage tool.

Methods: Cohort 1 consisted of 2,502 users who accessed the public website. Cohort 2 consisted of 194 new patients in a Comprehensive Breast Center setting. For patient users, we assessed documentation of family history and genetics referral. For all users seen in a genetics clinic, the Family HealthLink assessment was compared with that performed by genetic counselors and genetic testing outcomes.

Results: For general public users, the percentage meeting high-risk criteria were: for cancer only, $22.2 \%$; for coronary heart disease only, $24.3 \%$; and for both diseases, $10.4 \%$. These risk stratification percentages were similar for the patient users. For the patient users, there often was documentation of family history of certain cancer types by oncology professionals, but age of onset and coronary heart disease family history were less complete. Of 142 with high-risk assignments seen in a genetics clinic, $130(91.5 \%)$ of these assignments were corroborated. Forty-two underwent genetic testing and 17 (40.5\%) had new molecular diagnoses established.

Conclusion: A significant percentage of individuals are at high familial risk and may require more intensive screening and referral. Interactive family history triage tools can aid this process.

Genet Med advance online publication 30 October 2014

Key Words: familial; family history; genetic testing; risk assessment; triage

also have the potential to be highly effective in the context of the behavioral intention of the individual user. ${ }^{21,22}$

The authors have developed multiple iterations of interactive family history collection and assessment tools. The original JamesLink family history tool was available on touch-screen kiosks located in a comprehensive cancer hospital and a highrisk breast satellite clinic $^{8}$; it was then repurposed and made available online. JamesLink provided assessment for hereditary cancer risk. Medical records comparison of JamesLink patient users in the oncology setting showed that the rate of family history collection (69\%) by health-care providers was inadequate. ${ }^{8}$ Furthermore, only $14 \%$ of high-risk cancer classifications were identified, with $6.9 \%$ appropriately referred for genetic counseling. ${ }^{8}$ The investigators also found, through focus group study, a lack of response by patient users to the JamesLink risk message without reinforcement from an involved practitioner. $^{8,23}$ Subsequently, a third-generation tool, known as Family HealthLink, was developed that assesses risk for hereditary cancer syndromes and for familial coronary heart disease (Supplementary Material online). Family HealthLink users enter demographic information, personal cancer and coronary heart disease history, and history of first-degree and seconddegree relatives through a Web portal. ${ }^{24}$ The family history risk assessment (high, moderate, average; Figure 1) is stratified

\footnotetext{
${ }^{1}$ Division of Human Genetics, Department of Internal Medicine, Ohio State University Wexner Medical Center, Columbus, Ohio, USA; ${ }^{2}$ Department of Internal Medicine, Dorothy M. Davis Heart and Lung Research Institute, Ohio State University Wexner Medical Center, Columbus, Ohio, USA; ${ }^{3}$ Department of Internal Medicine, Stefanie Spielman Comprehensive Breast Center, Ohio State University Wexner Medical Center, Columbus, Ohio, USA; ${ }^{4}$ Department of Internal Medicine, Center for Biostatistics, Department of Biomedical Informatics, Columbus, Ohio, USA; ${ }^{5}$ Division of Surgical Oncology, Department of Internal Medicine, Ohio State University Wexner Medical Center, Columbus, Ohio, USA. Correspondence: Kevin Sweet (Kevin.Sweet@osumc.edu)
} 
using scoring algorithms developed from published literature., A qualitative message communicates risk and prompts users to discuss the assessment with their health-care providers. The qualitative message is also tailored with recommendations for screening and prevention based on personal risk level. ${ }^{25}$ The scoring algorithms used in calculating risk and recommendations are incorporated into a PDF summary for use by healthcare providers. Family HealthLink also prompts high-risk users to seek genetic counseling referral by speaking with health-care providers about their risk assessment. Resources for access to genetic counselors and for making an appointment in the Ohio State University Wexner Medical Center (OSUWMC) Division of Human Genetics clinic are provided in the PDF summary.

Family HealthLink has been available online since October 2008. Using two separate user cohorts, we sought to determine the effectiveness of Family HealthLink as a clinical triage tool. User cohort 1 consisted of 2,502 users from the general public who accessed the Family HealthLink website on their own. Cohort 2 comprised 194 new patient users in a Comprehensive Breast Center setting. Patient participants were offered use of Family HealthLink during initial registration. A printed copy of the Family HealthLink PDF risk report was provided to the patients before their appointments and for sharing with the oncology team the same day. Each cohort was retrospectively analyzed for the percentage with clinically significant family histories and accuracy of the risk assignment. For the Comprehensive Breast Center patient cohort specifically, we also determined how often cancer and coronary heart disease family history was accurately documented in the electronic medical record by oncology providers; and for those at high risk, if a genetic referral was made. For any Family HealthLink users subsequently seen in the OSUWMC Division of Human Genetics clinic, risk stratification and genetic testing outcomes were examined.

\section{MATERIALS AND METHODS}

\section{Study design}

Cohort 1: General public users. Cohort 1 consisted of general public users who accessed the Family HealthLink website on their own. Since launch of the tool online, OSUWMC marketing has advertised availability on the main hospital website, on the James Cancer Hospital website, and through numerous local community events. Family HealthLink has been listed as a general public resource for family history tools on the National Human Genome Research Institute website and other governmental websites (e.g., US Department of Health and Human Services). In June 2009, it was promoted through a Wall Street Journal article "The Life-Saving Secrets in Your Family Tree," ${ }^{26}$ and it has also been advertised on WOSU radio and via other local media outlets (i.e., local television news affiliates).

An institutional review board-approved protocol allowed investigators to access and analyze targeted deidentified data collected from 2,502 consecutive users over a 48-month period (1 October 2008 to 30 September 2012). A separate institutional review board-approved retrospective chart review protocol allowed investigation of 142 of these general public users who accessed OSUWMC genetic counseling services during the study period. At their clinical appointment, each of the 142 patients provided the PDF copy of the Family HealthLink risk summary, which was placed in their paper medical record. A chart review compared information the general public user entered into Family HealthLink, (e.g., proband age and medical history; number of family members with cancer and/or coronary heart disease; degree of relation of the family member to the proband; age at diagnosis) with that provided during the genetic counseling session. The risk stratification by Family HealthLink was then compared with that provided by the genetic counselor. If genetic testing was performed, outcomes were recorded.

Cohort 2: Patient users. Cohort 2 consisted of patient users who accessed the website in an oncology setting. The OSUWMC Stefanie Spielman Comprehensive Breast Center provides service for the care of individuals with breast cancer or who are at increased risk for development of breast cancer. At the time of this study, there were six surgical oncologists, seven medical oncologists, and five nurse practitioners providing care at this facility. For this study, one surgical oncologist, also trained as a clinical cancer geneticist and an attending physician in the OSUWMC Division of Human Genetics, acted as the control physician, whereas the remaining 17 physicians/practitioners comprised the comparison group. An educational in-service session focusing on Family HealthLink was offered to the comparison group before launch of the study, but attendance was not mandatory. Family HealthLink was subsequently made available (but not required) as part of new patient registration over a 20-month period (1 April 2011 to 31 December 2012). Registrars assisted any patient by typing in their verbal family history information on a desktop PC and then provided a printed copy of the PDF risk summary before their appointment with the oncology team. Retrospective electronic medical record (EPIC) comparison was performed to determine the details of family history collected by the medical provider (e.g., proband age and medical history; number of family members with cancer and/or coronary heart disease; degree of relation of the family member to the proband; age at diagnosis) as compared with those entered into Family HealthLink by the patient user. We also recorded, for 194 consecutive patient users, whether the medical provider cited specific family history information as part of the overall risk assessment, and whether genetics referral was made on the same day of service. The risk stratification by Family HealthLink was then compared with that provided by a genetic counselor. If genetic testing was performed, outcomes were recorded.

\section{Data curation and statistics}

Both cohorts were retrospectively analyzed and compared for the percentage with clinically significant family histories and for the percentage of users with a personal history of disease, to determine differences between user groups. Data sets were edited (to ensure uniformity of group identifiers) and descriptive statistics 
were generated using JMP software (JMP, version 9.0.0., SAS Institute, Cary, NC; 1989-2007). Two-tailed Fisher's exact test (FET) results were calculated using the "fisher.test" function in the $\mathrm{R}$ programming language ( $\mathrm{R}$ : A language and environment for statistical computing; R Foundation for Statistical Computing, Vienna, Austria; http://www.R-project.org/).

\section{RESULTS}

\section{Cohort 1: general public users}

Clinically significant family history. Over a 4-year period, there were 3,944 general public entries, based on IP address. Google Analytics showed users from 10 different countries and 806 cities; $93.7 \%$ were from the continental United States, and, of these, approximately one-third were from the Franklin County, Ohio, area. Sufficient information for Family HealthLink assessment was provided by 2,592 (65.7\%) entries, whereas 1,352 entries had insufficient usage or were excluded because of being return users; 2,502 (96.5\%) were correctly assessed by the scoring algorithms. The percentage meeting high-risk criteria were: cancer only, $22.2 \%$; coronary heart disease only, $24.3 \%$; high risk for both diseases, $10.4 \%$ (260) (Table 1). Of 612 users with a personal history of disease, 425 (69.4\%) had early-onset diagnosis: 98 with coronary heart disease and 327 with cancer.

The mean age of the 2,502 general public users was 44.2 years (SD: 14.0 years); 2,022 (80.8\%) were female and 480 were male participants (19.2\%). Of the 84 users not assessed by the Family HealthLink algorithms, 75 had entered more than one coronary heart disease diagnosis for a given family member, and

\section{Table 1 Cohort 1}

\begin{tabular}{ll} 
Risk stratification & \multicolumn{1}{c}{ Number } \\
\hline Classification & \\
\hline High risk & \\
Cancer & $556(22.2 \%)$ \\
Coronary heart disease & $608(24.3 \%)$ \\
Both diseases & $260(10.4 \%)$ \\
Moderate risk & $357(14.3 \%)$ \\
Average risk & $721(28.8 \%)$ \\
$\quad$ Subtotal & $2,502(96.5 \%)$ \\
\hline Demographics & \\
Age (mean, SD) & 44.2 years (14.0) \\
Gender (F:M) & $2,022: 480$ \\
\hline Incorrect application of algorithms & \\
Cancer & $9(0.33 \%)$ \\
Coronary heart disease & $75(2.70 \%)$ \\
Data entry inaccurate (ages, other) & $6(0.22 \%)$ \\
Subtotal & $90(3.5 \%)$ \\
\hline Users assessed & 2,592 \\
\hline Insufficient usage/repeat user & 1,352 \\
\hline Total & 3,944 \\
\hline
\end{tabular}

F, female; M, male.

${ }^{a}$ Although some users may be at high or moderate risk, only the high-risk classification was accounted for. ${ }^{b}$ Accounts for users at moderate risk only, for cancer and/or coronary heart disease. automated risk algorithms were incorrectly applied. Likewise, for nine individuals the cancer algorithms failed because more than one primary cancer was incorrectly applied. An additional six individuals entered invalid ages.

Genetic counselor assessment, genetic testing. Retrospective chart review study was performed for 142 general public users seen for genetics consultation (Table 2). Ninety-six (67.6\%; group A) had Family HealthLink assessments that matched those of the genetic counselor. Group B consisted of 46 users (32.4\%) for whom genetic consultation further refined the Family HealthLink assessment. Fifteen had additional risk factors that the Family HealthLink tool was not designed to identify. For example, four users initially classified as having high familial coronary heart disease risk were found to have specific forms of familial cardiovascular disease (e.g., familial LMNA-associated dilated cardiomyopathy). Thirty-one users had additional, different, or more specific family history collected during their genetics consultation. For the 96 users with genetics consultation confirmation of high-risk cancer status, 32 underwent genetic testing and 14 new molecular diagnoses were established (Table 2). For the 35 with high-risk coronary heart disease assignments confirmed, none underwent genetic testing.

\section{Cohort 2: patient users}

Electronic medical record comparison. One hundred ninetynine patients opted for Family HealthLink use in the oncology setting. According to the electronic medical records, $71(35.7 \%)$ had a current or previous diagnosis of cancer and 7 (3.5\%) had a history of coronary heart disease (Table 3). Twenty-eight had early-onset cancer diagnosis (before age 50), with 22 of these diagnoses being early-onset invasive breast cancer. One hundred seventy-eight (89.4\%) were seen by the comparison physician group, whereas 21 (10.5\%) were seen by the control physician. For the comparison group, the electronic medical record family history entry was complete for both diseases and concurred with the Family HealthLink patient user entry on 43 (24.2\%) records, as compared with the control $(11 / 21 ; 52.3 \%$; FET, $P=0.009$; Table 4$)$. Thirty-eight $(21.5 \%)$ patients in the comparison group had incomplete cancer and coronary heart disease family histories recorded; for an additional 67 (37.9\%) patients, only the coronary heart disease family history was incomplete. There was no electronic medical record family history documented in 15 (8.5\%) comparison group participant records. For the control group, there were incomplete cancer and coronary heart disease histories recorded in one (4.8\%; FET, $P=0.08$ vs. comparison group) record, whereas the coronary heart disease family history entry alone was incomplete in nine (42.9\%) records (FET, $P=0.8$ vs. comparison group).

Clinically significant family history. Family HealthLink correctly stratified risk for 194 (97.5\%; Table 4) patient users. The coronary heart disease risk algorithms were incorrectly applied in five cases, as more than one coronary heart disease diagnosis was entered for a given family member, and the 
Table 2 Cohort 1: Genetic counselor assessment

Group A: initial risk-corroborated

\begin{tabular}{|c|c|c|c|}
\hline FHL assessment & Corroborated & Genetic testing & Mutation positive \\
\hline \multicolumn{4}{|l|}{ High risk } \\
\hline $\mathrm{HBOC}$ & 44 & 16 (BRCA) & 9 \\
\hline \multirow[t]{2}{*}{$\mathrm{HBOC} / \mathrm{CHD}$} & 16 & 8 (BRCA) & $4^{b}$ \\
\hline & & 1 (BROCA panel) & - \\
\hline \multirow[t]{2}{*}{ CRC } & 4 & 1 (LS panel) & 1 \\
\hline & - & $1(\mathrm{IHC} / \mathrm{MSI})^{\mathrm{a}}$ & - \\
\hline MEN/CHD & 1 & - & - \\
\hline $\mathrm{TH}$ & 1 & - & - \\
\hline RB & 1 & - & - \\
\hline $\mathrm{MEL} / \mathrm{CHD}$ & 2 & - & - \\
\hline $\mathrm{CHD}$ & 15 & - & - \\
\hline OV & 2 & 1 (BROCA panel) $^{c}$ & 0 \\
\hline $\mathrm{TH}$ & 1 & - & - \\
\hline $\mathrm{CHD}$ & 3 & - & - \\
\hline Total & 96 & 28 & 14 \\
\hline \multicolumn{4}{|c|}{ Group B: initial risk—refined (46) } \\
\hline \multicolumn{4}{|c|}{ Risk factors not identified by FHL (15) } \\
\hline FHL assessment (no.) & Modified assessment (reason) & & Gene test results \\
\hline HR LFS/HR CHD (1) & HR LFS/FH of dilated cardiomyopathy & & LMNA mutation \\
\hline 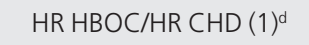 & HR HBOC/FH of hypertrophic cardiomyopathy & & \\
\hline $\mathrm{HR} C H D(1)$ & Hereditary arrhythmias & & \\
\hline $\operatorname{MRCHD}(1)^{d}$ & HR CHD/polyposis (FHL does not assess polyp history) & & \\
\hline $\mathrm{HR} C R C(1)$ & MR colon (records modified risk) & & \\
\hline HR HBOC (3) & MR BR (records modified risk) & & \\
\hline \multicolumn{4}{|c|}{ Additional or different family history (31) } \\
\hline $\mathrm{HR} \operatorname{HBOC}(5)^{\mathrm{d}}$ & $\mathrm{HR} \mathrm{HBOC} / \mathrm{MR}$ CHD & & $B R C A$ negative (2) \\
\hline $\mathrm{HR} H B O C / H R C H D(8)^{d}$ & $\mathrm{HR} \mathrm{HBOC} / \mathrm{MR} \mathrm{CHD}$ & & $B R C A$ negative (3) \\
\hline $\mathrm{HR} \mathrm{HBOC} / \mathrm{MR} \mathrm{CHD}(1)^{\mathrm{d}}$ & $\mathrm{HR} \mathrm{HBOC} / \mathrm{HR} \mathrm{CHD}$ & & \\
\hline $\mathrm{HR} \mathrm{HBOC}(1)^{\mathrm{d}}$ & $\mathrm{HR} \mathrm{HBOC} / \mathrm{HR} \mathrm{CHD}$ & & \\
\hline $\mathrm{HR} \mathrm{HBOC} / \mathrm{HR} \mathrm{CHD}(2)^{\mathrm{d}}$ & $\mathrm{HR} \mathrm{HBOC} / \mathrm{AV}$ CHD & & \\
\hline HR HBOC (3) & MR BR & & \\
\hline $\mathrm{HR} C \mathrm{CRC} / \mathrm{HR} \mathrm{CHD}(3)^{\mathrm{d}}$ & HR CRC/MR CHD & & \\
\hline $\mathrm{HR} C R C / \mathrm{HR} C H D(3)^{\mathrm{d}}$ & $\mathrm{HR} C \mathrm{CRC/AV} \mathrm{CHD}$ & & \\
\hline $\mathrm{HR}$ PR/HR CHD (1) & $\mathrm{HR} P R / M R \mathrm{CHD}$ & & \\
\hline $\mathrm{HR}$ CHD (3) & MR CHD & & \\
\hline MR CHD (1) & AV CHD & & \\
\hline
\end{tabular}

$A V$, average risk; BROCA, breast cancer panel test; $C H D$, coronary heart disease; CRC, colorectal cancer; FHL, Family HealthLink; HBOC, hereditary breast-ovarian cancer; HR, high risk; LFS, Li-Fraumeni syndrome; LS, Lynch syndrome; MEL, melanoma; MR, moderate risk; PR, prostate cancer; RB, retinoblastoma; TH, thyroid cancer.

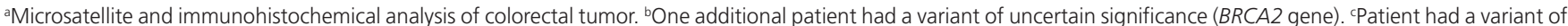
uncertain significance (ATM gene). Proband had personal history of papillary serous ovarian carcinoma (age 58); mother had gallbladder carcinoma; father had lung cancer.

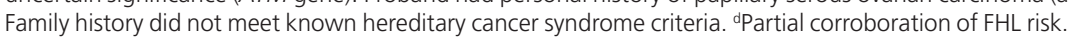


Table 3 Cohort 2: Clinical characteristics and electronic medical record comparison

Current or prior diagnosis

\begin{tabular}{|c|c|c|}
\hline Cancer type & $\begin{array}{l}\text { Late-onset } \\
\text { disease }\end{array}$ & $\begin{array}{l}\text { Early-onset } \\
\text { disease }\end{array}$ \\
\hline Invasive breast cancer & 29 & 22 \\
\hline DCIS & 11 & - \\
\hline LCIS & 2 & 2 \\
\hline Phylloides tumor & 1 & - \\
\hline Sarcoma & - & $1^{\mathrm{a}}$ \\
\hline Colorectal cancer & - & 1 \\
\hline Papillary thyroid cancer & - & 1 \\
\hline Melanoma & - & $1^{\mathrm{a}}$ \\
\hline Subtotal & 43 & 28 \\
\hline \multicolumn{3}{|l|}{ CHD type } \\
\hline $\mathrm{CHD}$ & 1 & - \\
\hline Myocardial infarction & 1 & - \\
\hline Stroke & 3 & 2 \\
\hline Total & 48 & 30 \\
\hline \multicolumn{3}{|c|}{ Electronic medical record comparison } \\
\hline Family history recorded & Active group & Control \\
\hline Complete family history & $44(24.7 \%)$ & $11(52.3 \%)$ \\
\hline Incomplete CHD family history & $67(37.6 \%)$ & $9(42.9 \%)$ \\
\hline Incomplete cancer family history & - & - \\
\hline No ages noted & $10(5.6 \%)$ & - \\
\hline $\mathrm{Br}$ Ca only noted & $4(2.2 \%)$ & - \\
\hline $\begin{array}{l}\text { Incomplete cancer and CHD } \\
\text { family history }\end{array}$ & $38(21.3 \%)$ & $1(4.8 \%)$ \\
\hline No family history & $15(8.4 \%)$ & - \\
\hline Total & 178 & 21 \\
\hline
\end{tabular}

$\mathrm{Br} \mathrm{Ca}$, breast cancer; CHD, coronary heart disease; DCIS, ductal carcinoma in situ; LCIS, lobular carcinoma in situ.

apatient also had history of DCIS.

computer algorithm incorrectly assigned increased risk. Of 194 correctly assigned patient users, the numbers meeting high-risk criteria were: cancer alone, 44 (22.1\%); coronary heart disease alone, 42 (21.6\%); high risk for both diseases, 17 (8.8\%). In total, six $(28.6 \%)$ patients seen by the control physician were at high risk and 97 (56.1\%) of comparison participants were at high risk (FET, $P=0.02$ ). The mean age of the 194 patient users was 53.4 years (SD: 13.1 years); 191 (98.5\%) were female and 3 were male participants (1.5\%).

Genetic counselor assessment, genetic testing. Of the 103 participants with correctly assigned Family HealthLink high-risk assignments, five had previous genetics evaluations (Table 5). Of the 98 participants with high-risk assignments eligible for genetics referral, $16(16.3 \%)$ had electronic medical record documentation of the referral. Specifically, for the comparison group, 7 of 37 (18.9\%) with high-risk cancer assignments only were referred, whereas for the control group, 1 of $3(33.3 \%)$ with high-risk cancer only assignment was referred (FET, $P=0.498$ ). Of 42 with high-risk coronary heart disease assignments, 2 of 41 were referred by the comparison group and 0 of 1 was referred
Table 4 Cohort 2: Family HealthLink assessment and physician referral

\begin{tabular}{|c|c|c|c|c|}
\hline $\begin{array}{l}\text { FHL } \\
\text { classification }\end{array}$ & $\begin{array}{c}\text { Number } \\
(\%)\end{array}$ & $\begin{array}{c}\text { Previously } \\
\text { seen }^{\mathrm{a}}\end{array}$ & $\begin{array}{c}\text { Eligible } \\
\text { for referral }\end{array}$ & $\begin{array}{l}\text { Genetics } \\
\text { referral }\end{array}$ \\
\hline \multicolumn{5}{|l|}{ High risk } \\
\hline $\mathrm{HBOC}$ & 35 & 4 & 31 & $7^{b}$ \\
\hline CRC & 3 & - & 3 & - \\
\hline LFS & 2 & - & 2 & - \\
\hline MEN & 1 & - & 1 & 1 \\
\hline Adrenal & 1 & - & 1 & - \\
\hline \multirow[t]{2}{*}{ Melanoma } & 2 & - & 2 & - \\
\hline & $44(22.7 \%)$ & & & \\
\hline CHD & 42 (21.6\%) & - & 42 & 2 \\
\hline Both diseases & $17(8.8 \%)$ & 1 & 16 & $6^{b}$ \\
\hline Subtotal & 103 & 5 & 98 & 16 \\
\hline Moderate risk & 30 (15.5\%) & - & - & 2 \\
\hline Average risk & 61 (31.4\%) & 2 & - & 3 \\
\hline Total assessed & $194(97.5 \%)$ & 7 & 98 & 21 \\
\hline \multicolumn{5}{|c|}{ Incorrect application of algorithms } \\
\hline $\mathrm{CHD}$ & $5(2.50 \%)$ & & & \\
\hline Total & 199 & & & \\
\hline
\end{tabular}

CHD, coronary heart disease; CRC, colorectal cancer; FHL, Family HealthLink; HBOC, hereditary breast-ovarian cancer; LFS, Li-Fraumeni Syndrome; MEN, multiple endocrine neoplasia.

aUsers previously seen through another medical center for genetics evaluation. ${ }^{\mathrm{b}} \mathrm{One}$ referred by the physician control.

by the control (FET, $P=1.0$ ). Six of the 16 patients with high risk assignments for both cancer and coronary heart disease were referred ( 1 of 1 in the control group, 5 of 15 in the comparison group; FET, $P=0.38$ ). An additional five patient users (two at moderate risk; three at average risk as assessed by Family HealthLink) were referred by the physician group.

For the 17 patients seen for genetics consultation, the Family HealthLink entry was corroborated. Of 13 patients meeting any high-risk criteria, 10 underwent genetic testing and 3 (33.3\%) had deleterious gene mutations. The one patient referred because of moderate risk had moderate risk status corroborated and did not undergo testing. Two of the three referred with average risk had personal diagnoses of invasive ductal carcinoma, were triple receptor-negative, and were age 41 and age 42 . Both individuals underwent genetic analysis, and one was found to have a deleterious $B R C A$ gene mutation; the other had a $B R C A$ variant of uncertain significance. The last average-risk referral had average risk status confirmed and did not undergo testing.

\section{DISCUSSION}

We have shown that Family HealthLink is an effective triage tool for assessment of cancer and coronary heart disease family histories. Identification of individuals at increased risk allows for incorporation of targeted screening at younger ages and, for those with family histories suggestive of hereditary disease that confer much higher risks, appropriate referral for genetic counseling and testing. In our series, risk stratification accuracy of 
Table 5 Cohort 2: Genetic counselor assessment

Corroborated risk

\begin{tabular}{lccc}
\hline $\begin{array}{l}\text { FHL } \\
\text { assessment }\end{array}$ & Corroborated & $\begin{array}{c}\text { Testing } \\
\text { (genes) }\end{array}$ & $\begin{array}{c}\text { Mutation } \\
\text { positive }\end{array}$ \\
\hline High risk & 10 & $7(B R C A)$ & 2 \\
HBOC & 1 & $1($ TP53; BRCA) & 1 \\
LFS & 1 & $1(B R C A)$ & 0 \\
HBOC/CHD & $1^{\text {a }}$ & $1(B R C A)$ & 0 \\
CHD & 13 & 10 & 3 \\
Subtotal & 1 & - & - \\
Moderate risk & 3 & $2(B R C A)^{b}$ & 1 \\
Average risk & 17 & 12 & 4 \\
Subtotal & & & \\
\hline Uncorroborated risk & 4 & 0 & 0 \\
\hline Not seen & 21 & 12 & 4 \\
Total & & & \\
\hline
\end{tabular}

CHD, coronary heart disease; FHL, Family HealthLink; HBOC, hereditary breastovarian cancer; LFS, Li-Fraumeni syndrome.

aproband had a personal history of breast cancer and chose to have BRCA analysis. ${ }^{b}$ Personal history of triple receptor-negative breast cancer-no supportive family cancer history.

the Family HealthLink algorithms, for both cancer and coronary heart disease, was high in both cohorts (public, $96.5 \%$; and patient, 97.5\%). Clinical validity of the cancer and coronary heart disease risk algorithms seems fair when compared with populationbased studies. ${ }^{915}$ Clinical trials of Family Healthware, an interactive online tool developed by the Centers for Disease Control and Prevention that stratifies familial risk for colon, breast, and ovarian cancer (among other diseases), showed at least 34\% of adult primary-care users were at high risk or moderate risk for at least one of these three cancer types. ${ }^{15}$ Likewise, the MeTree family history assessment tool, utilized in an unselected primary-care population, noted that $44 \%$ of patient users met higher risk criteria for increased management/prevention for breast/ovarian cancer, colon cancer, hereditary cancer syndromes, or thrombosis. ${ }^{27}$

In our series, 128 of 159 (80.5\%) of the Family HealthLink assignments across both cohorts were corroborated by a genetic counselor. One hundred thirteen (96 public; 17 patient) users had their Family HealthLink risk assessments validated outright. For 46 with assignments further refined by the genetic counselor, 15 had additional risk factors that the triage tool was not designed to identify (e.g., polyp history; pathology subtype), so, in essence, the Family HealthLink assignment was valid. For the 142 users from either cohort assigned high risk status, 130 (91.5\%) had this status corroborated. Obtaining and interpreting medical and family histories and documenting patient-reported diagnoses are cornerstones of the genetic counseling process. Comprehensive assessment by a genetic counselor can, in turn, be used to develop differential diagnoses, select the most appropriate genetic/genomic test to offer patients, and assist with the identification of at-risk family members. After genetic counseling, 42 users who had their Family HealthLink high-risk cancer assignment confirmed subsequently underwent genetic testing. Of these, 17 (40.5\%) had new molecular diagnoses established. Extrapolating from this, if all of the 877 patients with high-risk cancer assignments in this series were appropriately referred for genetic consultation and testing, and if $91.5 \%$ (802 users) were confirmed to be at high risk through genetic counseling, then 325 new molecular diagnoses would have been made. Likewise, a considerable number of high-risk coronary heart disease assignments would be appropriately confirmed. Evidence continues to accumulate regarding the cost-effectiveness of identifying individuals at higher risk and establishing effective cancer and coronary heart disease screening and prevention measures. ${ }^{28,29}$ Patients with hereditary forms of disease may also respond differently to standard treatments, necessitating and enabling more personalized approaches to care. . $^{3,30}$

Another clinically relevant finding was the incomplete documentation of family history and the focus on select cancers by oncology professionals. Although the oncology team surveyed had greatly improved documentation of family cancer history as compared with that previously shown $(91.5$ vs. $69 \%),{ }^{8}$ we found inadequate documentation of detail in approximately one-third (32.2\%) of records. Often there was a listing of the cancers in the family without age of diagnosis. There remained a focus on collecting cancer histories associated with the more common hereditary breast-ovarian cancer syndrome, without detail of other cancer types, which would be relevant for the more than 100 described Mendelian cancer syndromes. ${ }^{3,12}$ We also found inadequate information about generations beyond the immediate (first-degree) relatives. This incomplete family history documentation most likely affected the identification and referral of individuals at high risk. Of the 54 eligible patients with highrisk cancer classifications in cohort 2 seen by the physician comparison group, only $12(22.2 \%)$ were correctly referred. We did find increased awareness of early-onset and triple receptornegative invasive breast cancer, with the latter being an indicator for potential BRCA1 gene involvement, as a reason for genetics referral. In fact, 6 of $22(27.2 \%)$ of the patients with early-onset invasive breast cancer were appropriately referred. However, many high-risk cancer classifications (77.8\%) were missed, and those with other types of early-onset cancer (e.g., colorectal) were not referred. Similar issues were highlighted by the recent American Society of Clinical Oncology Quality Oncology Practice Initiative, which found that less than half (41.7\%) of oncology records documented ages of family members at cancer diagnosis and, likewise, a focus only on breast cancer. ${ }^{31}$ Additional studies have demonstrated the need for family history collection and clear referral guidelines for oncology professionals and primary-care providers alike., ${ }^{4,20,32}$

Third, we found incomplete coronary heart disease family history documentation (130 of $199 ; 65.3 \%)$ and referral by the oncology providers. In total, only $13.4 \%$ of those in cohort 2 with high-risk coronary heart disease classifications were referred; of these, only one had electronic medical record documentation of coronary heart disease family history as the reason. The lack of family coronary heart disease history documentation and referral was not necessarily surprising, given the oncology specialization. Nonetheless, failure to recognize risk can misguide oncology patients and providers alike, leaving them unaware 
- High risk: Personal or family histories suggestive for a hereditary cancer syndrome or familial coronary heart disease. Generally associated with an increased risk from two-to fivefold, with risk increasing based on the number of affected relatives, and early age of diagnosis. Individuals in this classification may be at increased risk for a germline mutation, and the option of genetic counseling and testing should be offered. Incorporation of increased surveillance and risk reduction/prevention strategies may be appropriate ${ }^{2,3,5,6}$

- Moderate risk: Personal or family histories conferring increased risk (relative risk of 2.0), requiring increased surveillance. Prevention strategies for individuals at moderate risk could include screening at earlier age and more frequently; more intensive screening methods; and lifestyle modification ${ }^{2,6}$

- Average risk (risk level of the general population): Personal or family histories that generally reflect later onset disease or no family history. These individuals typically do not require increased surveillance and standard public health recommendations apply

\section{Figure 1 Risk classification schema.}

of potentially harmful health risks and preventing implementation of appropriate management and risk-reduction strategies, especially with use of cardiotoxic treatments for breast cancer, specifically anthracyclines and trastuzumab. It should also be recognized that family history is a significant and independent predictor of risk, even in the presence of traditional risk factors (e.g., smoking, abnormal lipoprotein levels), and this is especially true for families with early-onset disease because a number of studies have noted increased risk for first-degree relatives. ${ }^{13,14,16,33}$ Working with their physician team, there is also great opportunity for prevention measures to be implemented with these individuals, such as diet modification, increased exercise, and smoking cessation, as well as hypertension, diabetes, and lipid screening and control. ${ }^{34,35}$

Although there was no electronic medical record inclusion of the Family HealthLink summary for cohort 2, anecdotally, some providers mentioned seeing summaries on the same day as the new patient visit. Many reported never seeing summaries. Thus, one study limitation was the potential for sharing of Family HealthLink information by the cohort 2 patients with the provider team. A second limitation is that despite documentation of referral, only 17 of $21(80.9 \%)$ of all referrals and 2 of 8 (25.0\%) with familial coronary heart disease from cohort 2 were seen for genetic consultation, so confirmation of high-risk status and medical diagnoses was not possible. Reasons for failure to either schedule or attend an appointment are unclear but need to be addressed. Patients undergoing active treatment may not be emotionally or psychologically ready for a genetics referral, and the oncology providers may be taking this into account. This limitation extends to the larger population-based cohort. Finally, we had incomplete information regarding the composition of the two cohorts. It remains possible that the populationbased cohort was more apt to seek online risk assessment tools and therefore more eager to follow up recommendations, such as seeking genetic counseling and testing, if at high risk. We also had limited information regarding the demographic makeup of the patient population, which, likewise, may have been more eager to learn about hereditary risks based on family history than other patients attending the Comprehensive Breast Center.

There is a need for efficient triage tools for incorporation into busy clinical practices to aid routine and systematic collection of family history, to standardize the assessment and referral process, and to improve the quality and cost-effectiveness of patient care. ${ }^{19,20,36}$ This is especially true for busy primarycare practices because a number of studies have shown that, on average, less than 10 minutes is spent collecting family history information for the purpose of patient assessment. ${ }^{37,38}$ Automated triage tools such as Family HealthLink also have the capacity to self-populate electronic medical records and, as such, directly affect clinical decision support. However, a more defined strategy for effective utilization and communication of the data generated and for incorporation of genetic counseling into the process is necessary. Interactive online tools also have the potential to effectively tailor and personalize messages for a single user. For lower-income and minority populations, such tools can be used to reinforce screening behaviors. ${ }^{39}$ Recently, Family HealthLink was repurposed as a downloadable application for portable devices, but it also remains available on the Internet. We hope this will allow even greater clinical utilization to augment identification of individuals at higher risk who are appropriate for screening and prevention programs, as well as allowing the opportunity for individual users to become more actively involved and engaged with their physician team toward better health care. ${ }^{18,36,38}$

In summary, we found that a significant percentage of individuals are at high familial risk for cancer and/or coronary heart disease and could benefit from genetic referral and more intensive screening. However, family history collection and assessment, even in the oncology specialty setting, remain inadequate. Our findings illustrate the need for interactive family history triage tools for clinical practice as well as for general public consumption to aid this process.

\section{SUPPLEMENTARY MATERIAL}

Supplementary material is linked to the online version of the paper at http://www.nature.com/gim

\section{ACKNOWLEDGMENTS}

The authors thank Shelly Hovick for her critical review of the manuscript. The authors thank Ferry Oriyo, Samantha DeMarsh, and David Newman for their invaluable assistance for this study. Research reported in this publication was supported by the OSUWMC Comprehensive Cancer Center. This study had no external funding.

\section{DISCLOSURE}

The authors declare no conflict of interest.

\section{REFERENCES}

1. Li R, Bensen JT, Hutchinson RG, et al. Family risk score of coronary heart disease (CHD) as a predictor of CHD: the Atherosclerosis Risk in Communities (ARIC) study and the NHLBI family heart study. Genet Epidemiol 2000;18:236-250.

2. Hampel H, Sweet K, Westman JA, Offit K, Eng C. Referral for cancer genetics consultation: a review and compilation of risk assessment criteria. J Med Genet 2004;41:81-91.

3. Garber JE, Offit K. Hereditary cancer predisposition syndromes. J Clin Oncol 2005;23:276-292. 
4. Moyer VA. Risk assessment, genetic counseling, and genetic testing for BRCArelated cancer in women: U.S. Preventive Services Task Force recommendation statement. Ann Intern Med 2014;160:271-281.

5. National Comprehensive Cancer Network I. Genetic/Familial High Risk Assessment. NCCN Clinical Practice Guidelines in Oncology, 2012. http://www. nccn.org/professionals/physician_gls/recently_updated.asp. Accessed 2013.

6. Scheuner MT, Whitworth WC, McGruder H, Yoon PW, Khoury MJ. Familial risk assessment for early-onset coronary heart disease. Genet Med 2006;8:525-531.

7. Morales A, Cowan J, Dagua J, Hershberger RE. Family history: an essential tool for cardiovascular genetic medicine. Congest Heart Fail 2008;14:37-45.

8. Sweet KM, Bradley TL, Westman JA. Identification and referral of families at high risk for cancer susceptibility. J Clin Oncol 2002;20:528-537.

9. Scheuner MT, McNeel TS, Freedman AN. Population prevalence of familial cancer and common hereditary cancer syndromes. The 2005 California Health Interview Survey. Genet Med 2010;12:726-735.

10. Scheuner MT. Genetic evaluation for coronary artery disease. Genet Med 2003;5:269-285.

11. Scheuner MT, Whitworth WC, McGruder H, Yoon PW, Khoury MJ. Expanding the definition of a positive family history for early-onset coronary heart disease. Genet Med 2006;8:491-501.

12. Nagy R, Sweet K, Eng C. Highly penetrant hereditary cancer syndromes. Oncogene 2004;23:6445-6470.

13. Murabito JM, Pencina MJ, Nam BH, et al. Sibling cardiovascular disease as a risk factor for cardiovascular disease in middle-aged adults. JAMA 2005;294:31173123.

14. Nadir MA, Struthers AD. Family history of premature coronary heart disease and risk prediction. Heart 2011;97:684; author reply 684.

15. Rubinstein WS, Acheson LS, O'Neill SM, et al.; Family Healthware Impact Trial (FHITr) Group. Clinical utility of family history for cancer screening and referral in primary care: a report from the Family Healthware Impact Trial. Genet Med 2011;13:956-965.

16. Flossmann E, Rothwell PM. Family history of stroke in patients with transient ischemic attack in relation to hypertension and other intermediate phenotypes. Stroke 2005;36:830-835.

17. Qureshi N, Armstrong S, Dhiman P, et al.; ADDFAM (Added Value of Family History in CVD Risk Assessment) Study Group. Effect of adding systematic family history enquiry to cardiovascular disease risk assessment in primary care: a matched-pair, cluster randomized trial. Ann Intern Med 2012;156:253-262.

18. Valdez R, Yoon PW, Qureshi N, Green RF, Khoury MJ. Family history in public health practice: a genomic tool for disease prevention and health promotion. Annu Rev Public Health 2010;31:69-87, 1 p following 87.

19. Wilson BJ, Carroll JC, Allanson J, et al. Family history tools in primary care: does one size fit all? Public Health Genomics 2012;15:181-188.

20. Lu KH, Wood ME, Daniels M, et al.; American Society of Clinical Oncology. American Society of Clinical Oncology Expert Statement: collection and use of a cancer family history for oncology providers. J Clin Oncol 2014;32:833-840.

21. Kelly KM, Sweet K. In search of a familial cancer risk assessment tool. Clin Genet 2007;71:76-83.
22. Kroeze W, Werkman A, Brug J. A systematic review of randomized trials on the effectiveness of computer-tailored education on physical activity and dietary behaviors. Ann Behav Med 2006;31:205-223.

23. Sweet KM, Willis SK, Ashida S, Westman JA. Use of fear-appeal techniques in the design of tailored cancer risk communication messages: implications for healthcare providers. J Clin Oncol 2003;21:3375-3376.

24. Family HealthLink [computer program]. The Ohio State University Wexner Medical Center, 2008. https://familyhealthlink.osumc.edu.

25. Kreuter MFD, Olevitch L. Tailoring Health Messages_Customizing Communication With Computer Technology. Lawrence Erlbaum Associates: Mahwah, NJ, 2000:145-164.

26. Mathews AW. The life-saving secrets in your family tree. Wall Street Journal 11 June 2009.

27. Orlando LA, Wu RR, Beadles $C$, et al. Implementing family health history risk stratification in primary care: impact of guideline criteria on populations and resource demand. Am J Med Genet C Semin Med Genet 2014;166C:24-33.

28. Saadatmand S, Tilanus-Linthorst MM, Rutgers EJ, et al. Cost-effectiveness of screening women with familial risk for breast cancer with magnetic resonance imaging. J Nat/ Cancer Inst 2013;105:1314-1321.

29. Bender R, Bell DA, Hooper AJ, et al. Screening for familial hypercholesterolaemia. Pathology 2012;44:122-128.

30. Brennan $\mathrm{P}, \mathrm{Claber} \mathrm{O}$, Brennan T. Cancer family history triage: a key step in the decision to offer screening and genetic testing. Fam Cancer 2013;12:497-502.

31. Wood ME, Kadlubek P, Pham TH, et al. Quality of cancer family history and referral for genetic counseling and testing among oncology practices: a pilot test of quality measures as part of the American Society of Clinical Oncology Quality Oncology Practice Initiative. J Clin Onco/ 2014;32:824-829.

32. Vasen $H F$, Möslein $G$, Alonso A, et al. Recommendations to improve identification of hereditary and familial colorectal cancer in Europe. Fam Cancer 2010;9:109-115.

33. Michos ED, Vasamreddy CR, Becker DM, et al. Women with a low Framingham risk score and a family history of premature coronary heart disease have a high prevalence of subclinical coronary atherosclerosis. Am Heart J 2005; 150: 1276-1281.

34. Kromhout D, Menotti A, Kesteloot H, Sans S. Prevention of coronary heart disease by diet and lifestyle: evidence from prospective cross-cultural, cohort, and intervention studies. Circulation 2002;105:893-898.

35. Stampfer MJ, Hu FB, Manson JE, Rimm EB, Willett WC. Primary prevention of coronary heart disease in women through diet and lifestyle. N Eng/ J Med 2000;343:16-22.

36. Sweet K, Michaelis, R. The Busy Physician's Guide to Genetics, Genomics and Personalized Medicine. Springer: Dordrecht, The Netherlands, 2011.

37. Acheson LS, Wiesner GL, Zyzanski SJ, Goodwin MA, Stange KC. Family historytaking in community family practice: implications for genetic screening. Genet Med 2000;2:180-185.

38. Guttmacher AE, Collins FS, Carmona RH. The family history-more important than ever. N Engl J Med 2004;351:2333-2336.

39. Skinner CS, Strecher VJ, Hospers H. Physicians' recommendations for mammography: do tailored messages make a difference? Am J Public Health 1994;84:43-49. 